\title{
Social e em rede
}

\section{lsabel Aleixo}

\begin{abstract}
"O nosso desejo é o de melhor conhecer o mundo que habitamos, para que possamos transformá-lo da melhor maneira. 0 teatro é uma forma de conhecimento e deve ser também um meio de transformar a sociedade. Pode nos ajudar a construir o futuro, em
\end{abstract} vez de mansamente esperarmos por ele. (Boal 2008: XI)

"Mudam-se os tempos, mudam-se as vontades" e, seja pela vivência político-económica dos tempos que se impõem ou seja pela emergência/necessidade da própria mudança, em tempos de redes sociais, vem à rede o tempo do Teatro Social.

Um Teatro Social que, por um lado, repesca as referências de Piscator, Brecht, Grotowsky e Boal; por outro, traduz uma renovação de pesquisas, teorias e práticas teatrais, centrando-se num processo que evidencia o teatro como formação, emancipação e valorização do indivíduo e/ou da comunidade.

0 teatro renova-se, deste modo, numa acção artística simultaneamente social e cultural, conjugando os domínios da ética e da estética, consubstanciando-se no respeito pelos sujeitos envolvidos no processo criativo, pelas suas histórias de vida e pelas suas volições.

Os sujeitos - entenda-se: as comunidades - são simultaneamente a finalidade e a condição necessária do processo criativo, favorecendo uma experiência de pluralidade e diversidade enquanto recurso criativo e social.

0 Teatro Social evidencia a perspectiva artística, apoiando-se num sólido processo criativo e num estruturado trabalho de actor, procurando dar voz a determinada comunidade. Equaciona-se, assim, a mudança social através da democratização da linguagem teatral e da criatividade.

Nos tempos actuais - os do apelo a uma "aldeia global" - o teatro deve explicitar claramente a sua função, o seu empenho, as suas orientações. Nesta óptica, as abordagens possiveis serão tantas quantas os contextos de aplicação e os interesses das comunidades envolvidas.

E é assim que, face ao interesse da comunidade leitora do Em rede, propomos uma breve incursão por três paises: Brasil, Espanha e Portugal.

Do Brasil o www.teatrosocial.org reencaminha-nos de imediato para http://teatrosocialbrasil.blogspot.com. É um sitio recente (2011), facilitado por Giulio Vanzan, no qual ele pretende dar conta do projecto que leva actualmente a cabo no Brasil. Para os estudiosos e curiosos do Teatro Social, este blogue presta informações diferenciadas sobre acções de formação neste domínio (veja-se a este propósito "O cardápio das nossas propostas" e "Início"),

disponibilizando também, na barra lateral, diversos vídeos e slides, ilustrativos de alguns dos trabalhos desenvolvidos nos cursos de formação ministrados.

É de interesse conferir os itens "O que é Teatro Social", "Porque se faz Teatro Social", "Como se desenvolve o percurso" e "As fases", que dão conta do processo de trabalho de Giulio Vanzan. Aqui se procede, respectivamente, a uma breve descrição, sem indicação de pormenores, no que à história do Teatro Social diz respeito; apresenta-se a finalidade geral de um projecto desta natureza; avançam-se as fases de desenvolvimento do percurso para os interessados nesta prática e apresentam-se possiveis etapas de condução de um projecto de Teatro Social.

De espreitar, ainda, "Parceiros\&tAmigos", onde são apresentados outros endereços que nos permitem rumar a outras experiências neste domínio (no Brasil, em França e em Itália).

De Espanha, http://www.laquintanateatro.com é um sítio em funcionamento desde 2008.

Assim que abrimos o sítio, surgem duas possibilidades de o abordar clicando em "Victoria Teijeiro" (onde a própria se apresenta, dando conta do seu percurso pessoal e de como formou o grupo), ou em "La Quintana Teatro". Seleccionada esta opção, surge-nos no monitor a informação sobre os propósitos e a origem da companhia.

Na página principal, na barra superior, o trabalho da companhia é-nos apresentado através de "Espectáculos", "Calendario", "Prensa", "Contacto".

Nos "Espectáculos" podemos visitar Innómines camino a felicidad e Desde lo invisible. A cada um destes espectáculos corresponde um dossiê temático, tendo o utilizador acesso ao "Argumento", "Elenco", "Proceso de Creación", "Necesidades Técnicas", "Fotos" e "Vídeo" de cada um, quer seja na perspectiva da aquisição desse mesmo espectáculo, quer seja na averiguação da temática e dos processos de construção inerentes a cada espectáculo.

Em "Calendario" é-nos dado um historial da carreira dos espectáculos de La Quintana Teatro, diferenciandose a carreira dentro e fora do pais. De igual modo, "Prensa" oferece-nos dois percursos "Críticas y opiniones" e "Gira Internacional". Aqui, o utilizador tem acesso a documentos diversos, sendo a maior parte deles críticas e opiniões sobre os espectáculos que a companhia tem em cena.

Do lado esquerdo do monitor, novos itens que se relacionam com a vida da companhia ("Noticias"; "Docencia Teatral"; "Libro de visitas" e "Enlaces"); do lado direito o destaque vai para o facto de a companhia ter sido distinguida pelos "Premios Max de las artes escénicas" (e, clicando, obtemos informação sobre a que corresponde esse galardão).
Isabel Aleixo

tem uma pósgraduação em Teatro e Comunidade e é actualmente professora de teatro. 
Cartaz do Curso de

Capacitação de

Facilitadores de Teatro Social, São Paulo, Brasit,

2011

Mapas do crescer-

Estação B - Adolescer, Centro Cultural de Belém,

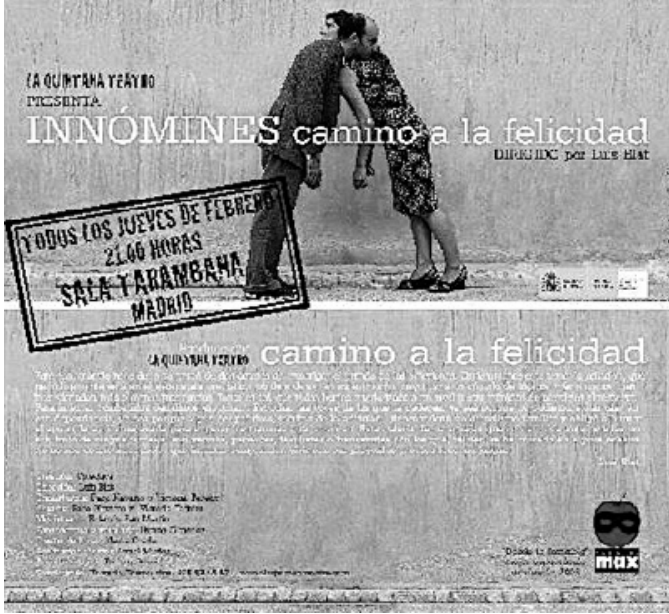

Regressando à esquerda do monitor, "Notícias" é, talvez, o elo mais actualizado para o que em La Quintana Teatro se faz, dando conta dos espectáculos Mira quien la Palma e Realidades.

De Portugal, http://teatrodebate.com.sapo.pt Talvez porque o que mais interessa ao Teatro Social é o lado humano, aqui, mal se abre o sítio, em primeiro lugar destacam-se as "Pessoas" que integram o projecto. Abrindo, podemos aceder à equipa e, em alguns casos, aceder aos currículos, mais ou menos completos e actualizados, dos quais destacamos o de Rita Wengorovius, fundadora do Teatro Umano, em 1998.

Para que não restem quaisquer dúvidas, "O que" explicita conceitos inerentes ao Teatro Social, assim como se contextualiza o seu aparecimento, identificado com o trabalho de Augusto Boal. Textos informativos, a merecerem consulta, sobre "0 Universo do Teatro Político Social", "0 Teatro Debate e a formação" e "Teatro Debate para adolescentes".

Em "Espectáculos" espreitamos sinopses e fotografias dos espectáculos realizados e disponiveis para itinerância tal como em "Formação" averiguamos o conjunto de acções de formação facilitadas pelo Teatro Umano.

"Quem somos" apresenta-nos um breve historial da companhia, com a lista de espectáculos apresentados de 2000 a 2005. Dai em diante, o trabalho do Teatro Umano deixa de estar actualizado neste sítio para, mais recentemente, passar a ser possivel acompanhar as suas acções através do Facebook. Apesar desta aparente desactualização, optámos por manter a referência ao sítio na medida em que, além de conter informação que consideramos importante, temos conhecimento de que o mesmo está a ser reestruturado, estando para breve a reactivação do seu funcionamento.

Sempre que abrimos um dos tópicos supracitados, no lado esquerdo do monitor surgem várias possibilidades, retomando os itens de abertura do sítio e explicitando as fotos (presentes, especialmente a acompanhar os espectáculos) em "Galeria" e acrescentando o item "Questionário", por forma a obter uma opinião por parte de quem assistiu e/ou participou em alguma das sessões do Teatro Umano.

Para finalizar, no rodapé do sítio, encontra-se disponivel para consulta o "Manifesto 1" do Teatro Umano, assim como a ligação para o item "Com quem trabalhamos",
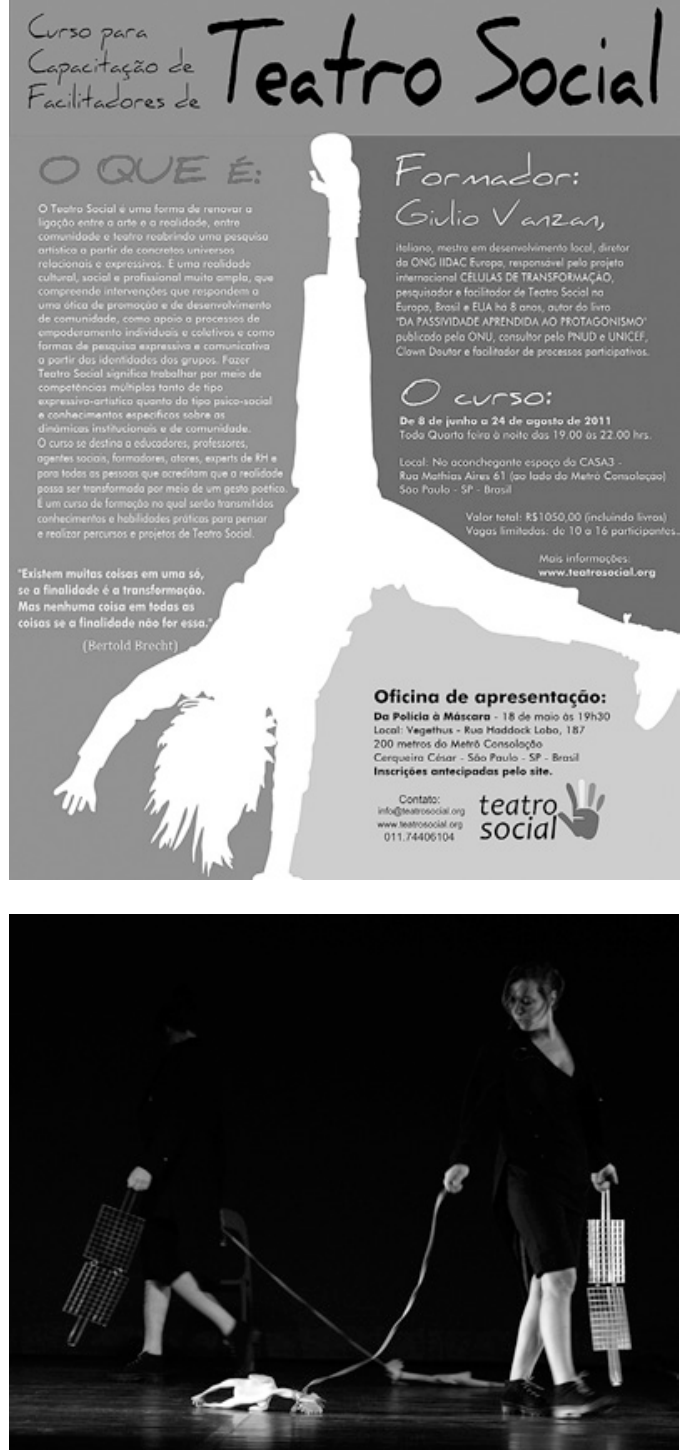

espelhando, também deste modo, o âmbito de intervenção do Teatro Umano por terras lusas, espanholas e italianas.

0 mesmo grupo encontra, como já foi dito, importantes actualizações da sua actividade na rede social Facebook sobretudo no que à produção de espectáculos diz respeito. Aqui predomina a informação visual, em detrimento da informação sobre o conteúdo das peças apresentadas. No item "Informação» podemos também verificar uma ampliação do âmbito de intervenção do Teatro Umano e, também, da sua fundamentação. Refira-se que o Teatro Umano constitui o objecto de estudo da tese de doutoramento que Rita Wengorovius se encontra a preparar e que apresentará à Universitá di Milano. Tratase de um exemplo que vem confirmar a atenção dispensada por investigadores e formadores, em Portugal e no estrangeiro, a este tema.

De rede em riste, aguardam-se novas actualizações de estado, no estado do Teatro Social.

\section{Referência bibliográfica}

BOAL, Augusto (2008), Jogos para atores e não-atores, Rio de Janeiro Civilização Brasileira. 